\title{
Desperdício nas Cadeias Agroalimentares no Contexto da Economia Circular
}

\author{
Waste in Agri-Food Chains in the Context of the Circular Economy
}

\author{
Omar Ouro Salim ${ }^{1 \mathrm{i}}$ \\ Patrícia Guarnieri ${ }^{2 i i}$ \\ Orcid: https://orcid.org/0000-0003-1792-4886 Orcid: https://orcid.org/0000-0001-5298-5348
}

\author{
Gisela Demo ${ }^{3 \text { iii }}$ \\ Orcid: https://0000-0003-1864-0471
}

\begin{abstract}
Resumo
O objetivo deste trabalho foi compreender o estado da arte na Economia Circular (EC) do desperdício de alimentos, por meio de revisão da literatura internacional. Para o levantamento das informações, foi utilizada a técnica da revisão sistemática de literatura (RSL), fundamentada no protocolo de Cronin, Ryan e Coughlan (2008), utilizando o recorte temporal dos últimos dez anos, 2010 a 2020. Esta RSL foi realizada em cinco bases: Web of Science, Scopus, Science Direct, Taylor e Francis e Emerald. As etapas foram descritas e, ao final, foram analisados 50 artigos. Os resultados apontam para um crescente interesse dos pesquisadores, principalmente na Europa, focados em tentativas de implementar modelos circulares que visem mitigar o desperdício alimentar, e que a transição para esses modelos é essencial devido ao esgotamento dos recursos naturais e externalidades socioeconômicas negativas. Tais resultados lançam luz a novas possibilidades de pesquisa e a políticas públicas para redução de desperdício que certamente engendrarão ganhos econômico, social e ambiental no contexto dos países em desenvolvimento. Por fim, sugere-se uma agenda de pesquisa para avanços de estudos na temática.
\end{abstract}

Palavras-chave: economia circular; desperdício de alimentos; sustentabilidade.

\begin{abstract}
The objective of this paper was to understand the state of the art in the Circular Economy (CE) of food waste through a review of international literature. The systematic literature review (SLR) technique, based on Cronin, Ryan and Coughlan (2008) protocol, was used to gather information, using the time clipping of the last ten years, 2010 to 2020. We performed the SLR on five bases: Web of Science, Scopus, Science Direct, Taylor and Francis and Emerald. We described the steps and, in the end, we analyzed 50 papers. The results point to a growing interest of researchers, mainly in Europe, focused on attempts to implement circular models aimed at mitigating food waste and the transition to these models is essential due to the depletion of natural resources and negative socioeconomic externalities. It is noteworthy that this research can bring economic, social and environmental gains in the context of developing countries. Finally, we suggest a research agenda for the advancement of studies on the subject.
\end{abstract}

Keywords: circular economy; food waste; sustainability.

\footnotetext{
${ }^{1}$ Universidade de Brasília - DF. Brasil. E-mail: ouromar@yahoo.fr

${ }^{2}$ Universidade de Brasília - DF, Brasil. E-mail: profpatriciaunb@gmail.com

3 Programa de Pós-Graduação em Administração da Universidade de Brasília (PPGA/UnB). E-mail: giselademo@gmail.com
} 


\section{INTRODUÇÃO}

O mundo precisa de alimentos para suprir as necessidades humanas. $\mathrm{O}$ reaproveitamento dos desperdícios alimentares, transformando-os em outros produtos, com valor agregado, recebeu atenção particular nessas últimas décadas, notadamente pelos benefícios trazidos para as empresas e sociedade. Nas cadeias de suprimentos alimentares (CSAs), a extensão da vida dos produtos alimentares consumíveis é uma necessidade para mitigar os problemas do desperdício alimentar. Há cerca de 366 mil toneladas de desperdício alimentar por ano nos diferentes estágios de distribuição varejista, e isso significa que todos os dias, as cadeias alimentares perdem grandes quantidades de produtos alimentícios (FRANCELLO et al., 2017).

Nesse contexto, vários países desenvolvidos implementaram nas suas políticas públicas os princípios da economia circular (EC) para mitigar os problemas de desperdício de alimentos e resguardar os recursos naturais que cada vez mais estão tornando-se escassos. Foi o caso do Japão, China, Holanda e Alemanha, países mais envolvidos nas técnicas circulares (LEMOS, 2018).

No entanto, no artigo de Sheppard et al. (2020), foram desenvolvidas ferramentas que incorporam um modelo lógico, a fim de identificar e quantificar fluxos de resíduos de alimentos em diferentes escalas. Essas ferramentas de conversão dos resíduos de alimentos em outras matérias-primas se revelaram eficazes, mas não suficientes para assegurar o gerenciamento de resíduos de alimentos em um nível subideal.

Slorach et al. (2020) analisam possíveis cenários futuros para $\mathrm{o}$ gerenciamento do desperdício de alimentos. Para eles, quaisquer compromissos para melhorar a sustentabilidade do tratamento de resíduos de alimentos devem ser acompanhados por uma estratégia eficaz de prevenção de resíduos.

A nano embalagem provou ser uma tecnologia promissora para prolongar significativamente a vida útil dos produtos alimentícios e uma solução potencial para a redução da fonte do desperdício de alimentos. Porém, a produção de nano materiais requer entrada extra de recursos e gera emissões e resíduos adicionais (ZHANG et al., 2019).

Por outro lado, os estudiosos apontam a necessidade de uso de técnicas de quantificação na redução do desperdício de alimentos nas cadeias de suprimentos agroalimentares, particularmente nas cadeias de valor do leite (WESANA et al., 2019).

No entanto, para que os estudos que quantifiquem essas perdas possam ser interpretados eficazmente é necessária uma padronização dos métodos utilizados para este fim. Assim, faltam estudos que adotem uma abordagem sistemática para contabilizar o desperdício de alimentos fornecendo valores desagregados por estágio da cadeia de suprimentos alimentar e por grupos de alimentos (CALDEIRA et al., 2019).

No entanto, existem estudos que focaram na redução de perdas e desperdício de alimentos. Por exemplo, Santos, Guimarães \& Junior (2019) analisaram estratégias de engajamento para lidar com o desperdício de alimentos em hospitais. Deliberador (2019) examinou o desperdício de alimentos em restaurantes universitários brasileiros. Creus (2018), por seu turno, trabalhou na quantificação dos desperdícios alimentares no Brasil.

Liu et al. (2020) estudaram a caracterização dos impactos ambientais dos desperdícios de embalagens gerados por serviços de entrega de alimentos 
urbanos na China. Dhir et al. (2020) analisaram os impactos do desperdício de alimentos nos serviços hoteleiros. Santos et al. (2020) discutiram as diferentes legislações em vigor, as quais estão prontas para serem implementadas no Brasil como parte da prevenção e redução do desperdício de alimentos.

Moraes et al. (2020) fizeram uma revisão sistemática de literatura que mapeia as causas dos desperdícios alimentares e as práticas de redução num contexto mais amplo da cadeia de abastecimento, particularmente em varejos.

Dora et al. (2021) realizaram uma revisão sistemática de literatura nos últimos 20 anos, sobre o desperdício de alimentos na cadeia de abastecimento dos países desenvolvidos e menos desenvolvidos. Annosi et al. (2021) abordaram a digitalização dentro das cadeias de abastecimento alimentar para prevenir o desperdício de alimentos.

Assim, existem estudos que tratam de setores específicos de perdas e desperdícios de alimentos Dhir et al. (2020), bem como estudos que relatam a conceituação da EC (GHISELLINI et al., 2016; KORHONEN et al., 2018; MERLI et al., 2018).

No entanto, existem poucas publicações em relação ao desperdício de alimentos, sob a ótica da economia circular - EC, pois ela está associada a uma variedade de conceitos provenientes da Academia como cradle to cradle, ecologia industrial, simbiose industrial, cadeia de suprimentos fechadas, entre outros e ainda carece de consolidação teórica. Além disso, a EC está vinculada ao conceito de desenvolvimento sustentável, apontando diversas formas de sua operacionalização em nível micro, meso e macro (GHISELLINI et al., 2016).

Portanto, nosso estudo tem como objetivo compreender o estado da arte no que tange ao desperdício de alimentos sob a ótica da EC, por meio de revisão sistemática de literatura internacional, com base no protocolo de Cronin, Ryan e Couglan (2008), cujos critérios de inclusão e exclusão foram delimitados na seção de métodos.

Por meio deste estudo, os formuladores de políticas públicas podem aprender lições sobre como agregar valor a partir da redução do desperdício de alimentos a fim de auxiliar e orientar os atores da cadeia de suprimentos de alimentos a se beneficiarem de um sistema alimentar circular. Pesquisadores que atuem na área também podem obter dados que indiquem possibilidades de estudos futuros.

\section{Fundamentação teórica}

\subsection{Economia circular}

As iniciativas setoriais da EC em países desenvolvidos, como Estados Unidos da América, Japão e Europa, têm se destacado em relação à gestão de resíduos (LUTTENBERGER, 2020). Além disso, novas iniciativas inovadoras de EC são incentivadas ao capacitar as pessoas para esforços colaborativos (LEVOSO et al., 2020).

$\mathrm{O}$ modelo 3R (Reduzir, Reutilizar, Reciclar), tem sido considerado como a fonte norteadora da EC em vários estudos realizados ao redor do mundo (KRISTENSEN e MOSGAARD, 2020). No processo de redução, a minimização de insumos por meio de aprimoramento da ecoeficiência e das normas de consumo resulta no uso de menos matérias-primas, energia não renovável e produção de resíduos (SU et al., 2013). O processo de reutilização é lucrativo para produtores, consumidores e ambientalistas, pois requer recursos limitados, como mão de obra e energia, em relação à fabricação de novos produtos com materiais virgens (CASTELLANI et al., 2015). 
$\mathrm{O}$ processo de reciclagem permite a extração do material reutilizável dos resíduos gerados no fim do ciclo de vida do produto, reduzindo seu impacto ambiental (JABBOUR et al., 2019). Ele é considerado paralelo ao modelo de EC, pois tem o potencial de reduzir os resíduos à zero (SONG et al., 2015). No entanto, a reciclagem tem um efeito contrário aos processos de redução e reutilização em termos de eficiência de recursos e sustentabilidade ambiental (GHISELLINI et al., 2016). A EC visa a redução na fonte, ou seja, partindo do design que prevê o design para desmontagem, uso de materiais mais sustentáveis, incluindo os biodegradáveis ou que sirvam como matéria-prima para ele ou outros processos produtivos. Muitos países, principalmente os em desenvolvimento, ainda focam na reciclagem como principal meio para viabilizar a transição da EC, mas o correto é também reduzir os insumos desde o planejamento, eliminando desse processo os rejeitos, que são aqueles para os quais não existe tecnologia ou viabilidade econômica para a reciclagem (GUARNIERI, CERQUEIRA-STREIT, BATISTA, 2020).

A EC tem como finalidade a busca incessante da eliminação do desperdício. Ela emerge como um modelo de desenvolvimento sustentável, regenerativo e restaurativo, cujo objetivo é manter produtos, resíduos alimentares e recursos naturais em seu mais alto nível de utilidade e valor no tempo, gerando benefícios sociais, econômicos e ambientais para a sociedade (ELLEN MacARTHUR FOUNDATION, 2015). A EC é um sistema industrial que visa substituir o conceito de fim de vida dos produtos por meio de ciclo fechado. A partir da EC, é possível eliminar o uso de produtos tóxicos que prejudicam à biosfera e os rejeitos. O escopo da EC é a redução dos resíduos, matérias-primas e produtos não renováveis, por meio de sistemas de produção fechada e novos modelos de negócios (EMF, 2014).

No entanto, não há um consenso sobre a origem da EC. Alguns autores ressaltam que ela tem suas origens na literatura da economia (BOULDING, 1966; PEARCE \& TURNER, 1990), ecologia industrial (FROSCH \& GALLOPOULOS, 1989; LIFSET \& BOONS, 2012) e sustentabilidade corporativa (LOVINS et al., 1999; BENYUS，2002; MCDONOUGH \& BRAUNGART, 2002; STAHEL, 2016; GUIDE \& VAN WASSENHOVE, 2009; PAULI, 2010, MURRAY et al., 2015), cujos conceitos começaram a impactar as comunidades acadêmica, empresarial e industrial.

A compreensão da EC e suas aplicações no sistema econômico atual e nos processos industriais progrediram e incorporaram diferentes conceitos que compartilham a ideia de ciclos fechados (GEISSDOERFER et al., 2017).

Para Andersen (2007), Ghisellini et al. (2016), Lieder e Rashid (2016), e Su, Heshmati, Geng \& Yu (2013), a EC tem recebido ampla atenção nas pesquisas acadêmicas e no design de produtos circulares (BAKKER et al., 2014). O trabalho da Ellen Foundation MacArthur na União Europeia, em relação aos benefícios da EC para o meio ambiente desde 2010, foi importante e chamou a atenção dos atores e políticos, influenciando assim governos e agências intergovernamentais em nível local, regional, nacional e internacional (GEISSDOERFER et al., 2017).

Destarte, a EC foi percebida como uma abordagem sistêmica e de múltiplos atores, em um contexto da cadeia de valor, ciclo de vida, inovação e transformações em direção ao desenvolvimento sustentável, conciliando diversos interesses. Ademais, ela vai muito além da reciclagem e do gerenciamento de resíduos. Este novo paradigma leva em consideração a vida útil dos produtos, 
materiais e recursos naturais utilizados na produção, transporte e consumo. Adicionalmente, a transição para uma EC envolve o uso mais eficiente dos recursos ao longo da cadeia de suprimentos e processos de consumo (SAUVÉ et al., 2016).

Portanto, o gerenciamento do desperdício de alimentos no contexto da EC pode ser observado em vários aspectos de acordo com os modelos de recuperação e valorização desses últimos. Nessa lógica, é indispensável medidas para o tratamento, medição e controle dos desperdícios alimentares gerados. Além disso, o desperdício de alimentos deve ser valorizado visando resultados social, econômico e ambiental (UNGER \& RAZZA, 2018).

\subsection{Desperdício de alimentos}

Alguns estudos distinguem resíduos inevitáveis, potencialmente evitáveis e evitáveis (WASTE AND RESOURCES ACTION PROGRAMME, 2009) e consideram os resíduos evitáveis apenas como desperdício, enquanto outros estudos não fazem essa distinção (ÖSTERGREN et al., 2014).

Sendo assim, a dificuldade vem do uso da palavra "perda" para certos atores (agricultura, indústria, agroalimentar) e da palavra "desperdício" para os consumidores, varejistas, atacadistas e atores de cadeias curtas, como feiras. $\mathrm{O}$ termo "desperdício" é mais negativamente conotado do que o termo "perda" e implica, em particular, uma certa responsabilidade/culpa daquele que desperdiçou o alimento. As duas expressões (perda e desperdício) não têm um vocabulário equivalente e são literalmente intercambiáveis. Por exemplo, a palavra em inglês waste significa ambos (desperdice, desperdício, perda / desperdício, lixo, esgoto, lixeira), dependendo do contexto. A palavra desperdício pode ser traduzida em inglês como waste, wastefulness, wastage, squandering... enquanto a palavra wastage em inglês, pode ser traduzida como desperdício ou perda (LE BORGNE, 2015).

Estudos realizados por Kinobe $e t$ al. (2015), em Uganda, mostram que dos produtos entregues no aterro, $\mathrm{o}$ desperdício de alimentos constituiu a maior quantidade (39\%), seguida pelos produtos vegetais $(23 \%)$. Os possíveis produtos recuperados de aterro são: plásticos, polietileno, macio, têxteis, papel e metal com as respectivas porcentagens: $31 \%, 37 \%, 15 \%, 12 \%$ e $5 \%$.

Segundo os dados registrados pela Food and Agriculture Organization of the United Nations (FAO, 2018), cerca de um terço de alimentos produzidos na Europa são desperdiçados. Os custos globais dos desperdícios alimentares excedem 1,7 milhões de dólares por ano. De acordo com a FAO, são responsáveis por $52 \%$ dos desperdícios os consumidores, $9 \%$ os varejistas, $17 \%$ a indústria transformadora e $23 \%$ a indústria produtora.

Diante do exposto, em relação à redução do desperdício de alimentos no mundo, os estudos têm se concentrado na quantificação e nas causas do desperdício de alimentos em diferentes cadeias produtivas. Por exemplo, Parfitt et al. (2010) realizaram uma revisão da literatura sobre a quantificação de resíduos alimentares em cadeias globais de abastecimento de alimentos, enquanto outros autores se concentraram em países específicos, como Suíça (BERETTA et al., 2013), Paquistão (TOSTIVINT et al., 2017), Estados Unidos, Reino Unido, França (MENA et al., 2014; Mourad, 2016), Canadá (DELORENZO et al., 2019) e países da Europa Ocidental (TELLER et al., 2018). Em contrapartida, existem poucos estudos realizados em países em desenvolvimento, o que constitui uma 
lacuna na literatura que a presente revisão buscou preencher (DORA et al., 2021).

\section{Métodos e técnicas de pesquisa}

Trata-se de uma pesquisa de natureza aplicada, no que tange aos objetivos é exploratória-descritiva, com abordagem qualitativa. No que se refere ao procedimento técnico da pesquisa, foi usada a revisão da literatura. É importante destacar que existem também dois tipos de revisão da literatura, conforme ressaltam Cronin, Ryan e Coughlan. (2008): revisão tradicional ou narrativa da literatura e revisão sistemática da literatura - RSL. A revisão tradicional não deixa explícitos os procedimentos usados para selecionar e filtrar os artigos, e possui maior subjetividade nas escolhas do pesquisador. Por outro lado, a RSL utiliza uma abordagem mais rigorosa e definida para revisar a literatura, deixando explícitos os critérios de inclusão, exclusão e filtragem dos artigos, portanto, fornece a análise crítica de artigos publicados da área de estudo em questão e dos autores do próprio artigo, para garantir sua robustez e replicabilidade (CRONIN, RYAN e COUGHLAN, 2008).

Assim sendo, a elaboração de um roteiro/protocolo de seleção de artigos é necessária para demonstrar a lacuna existente no escopo da intenção de pesquisa definida. Para isso, foi utilizado o Protocolo de Cronin, Ryan e Coughlan (2008), um procedimento composto por cinco etapas, são elas: 1. Formulação da questão de pesquisa; 2. Estabelecer conjunto de critérios de inclusão e exclusão; 3. Seleção e acesso da literatura; 4. Avaliação da qualidade da literatura incluída na revisão; 5. Análise, síntese e disseminação dos resultados, descritas no Quadro 1.

Quadro 1- Etapas da pesquisa

\begin{tabular}{|c|c|}
\hline Etapas & Caraterísticas \\
\hline $\begin{array}{l}\text { Questão de pesquisa da } \\
\text { RSL }\end{array}$ & $\begin{array}{l}\text { Quais são as principais características da literatura internacional que versa sobre a } \\
\text { redução do desperdício alimentar no âmbito da EC? }\end{array}$ \\
\hline $\begin{array}{l}\text { Definição do conjunto } \\
\text { de critérios de inclusão } \\
\text { e exclusão }\end{array}$ & $\begin{array}{l}\text { Os critérios abrangem a base científica selecionada, período de publicação, tipos } \\
\text { de artigos, palavras-chave e operadores booleanos. Devido ao fato de que o tema } \\
\text { que versa sobre a EC é multidisciplinar, e que pode ser encontrado em periódicos } \\
\text { de diversas áreas, definiu-se que a pesquisa ocorreria nas bases científicas Science } \\
\text { Direct, Scopus, Web of Science, Taylor \& Francis, e Emerald, as quais são } \\
\text { multidisciplinares e abrangem artigos de periódicos com alto fator de impacto e de } \\
\text { diversas áreas: Análise de Decisões; Administração; Engenharia da Produção; } \\
\text { Engenharia Civil; Engenharia Mecânica; Engenharia de Software; Tecnologia da } \\
\text { Informação; Economia; Ciências Contábeis; Matemática; entre outras. Em seguida } \\
\text { estabeleceu-se o período de publicação, o qual abrange artigos publicados de } 2010 \\
\text { até } 31 \text { de março de 2020. Quanto às palavras-chave, foram definidas as palavras } \\
\text { em inglês: "Circular Economy" AND "Food Waste". }\end{array}$ \\
\hline $\begin{array}{l}\text { Seleção e acesso da } \\
\text { literatura }\end{array}$ & $\begin{array}{l}\text { No tocante aos tipos de artigos, definiu-se que seriam abrangidos somente artigos } \\
\text { completos publicados em periódicos, o que excluiu artigos publicados em anais de } \\
\text { eventos, dissertações, teses, patentes, livros e capítulos de livros, erratas, entre } \\
\text { outros. No que se refere aos operadores booleanos utilizados, optou-se somente } \\
\text { pelo AND, excluindo-se os operadores } N O T \text { e } O R \text {. Para a primeira seleção, os } \\
\text { artigos deveriam versar sobre a recuperação e valorização do desperdício alimentar } \\
\text { de acordo com a leitura do título e resumo. Foram identificados, no total, } 216 \\
\text { artigos no período de } 2010 \text { até } 31 \text { de março de } 2020 \text {, dos quais, após a leitura dos } \\
\text { resumos (abstract) e títulos, foram excluídos } 166 \text { por não abordarem propriamente } \\
\text { o tema } F W \text { no contexto da EC. }\end{array}$ \\
\hline
\end{tabular}




\begin{tabular}{|l|l|}
\hline $\begin{array}{l}\text { Avaliação da qualidade } \\
\text { da literatura incluída na } \\
\text { revisão }\end{array}$ & $\begin{array}{l}\text { Constatou-se que apenas 50 se encaixavam no tema da pesquisa, ocorreu uma } \\
\text { repetição de 65 artigos nas cinco (5) bases escolhidas e os outros 101 foram } \\
\text { eliminados por se distanciarem do tema relacionado ao desperdício alimentar no } \\
\text { contexto da EC. Foram realizados o fichamento e compilação dos 50 artigos } \\
\text { restantes, destacando-se os aspectos relacionados à questão da pesquisa } \\
\text { previamente definida na etapa 1, envolvendo: autores; período de publicação; } \\
\text { subproblema relativo ao desperdício alimentar envolvendo o contexto da EC. }\end{array}$ \\
\hline $\begin{array}{l}\text { Análise, síntese e } \\
\text { disseminação dos } \\
\text { resultados }\end{array}$ & $\begin{array}{l}\text { Esta fase abrangeu a análise de cada artigo, necessária para a análise e interpretação } \\
\text { dos trabalhos publicados. Dessa forma, foram elaborados quadros, tabelas e figuras } \\
\text { com os principais critérios utilizados e respectivos autores. Os cinquenta (50) } \\
\text { trabalhos foram analisados rigorosamente. }\end{array}$ \\
\hline
\end{tabular}

Fonte: Autores.

Resumindo, a Figura 1 ilustra a pesquisa realizada e os resultados quantitativos encontrados em cada etapa. A seção resultados consistia em buscar artigos de todos os anos, que possuíssem os termos "Circular Economy" AND "Food Waste" no título ou no resumo ou nas palavras-chave dos trabalhos e corresponde somente aos artigos completos publicados em journals e em inglês. A filtragem 1 corresponde aos artigos que se repetem após análise e a seleção. A filtragem 2 satisfaz aos artigos que não possuíssem aderência com o escopo da pesquisa.

Figura 1-Pesquisa e seus resultados seguindo o Protocolo da Revisão Sistemática de Literatura
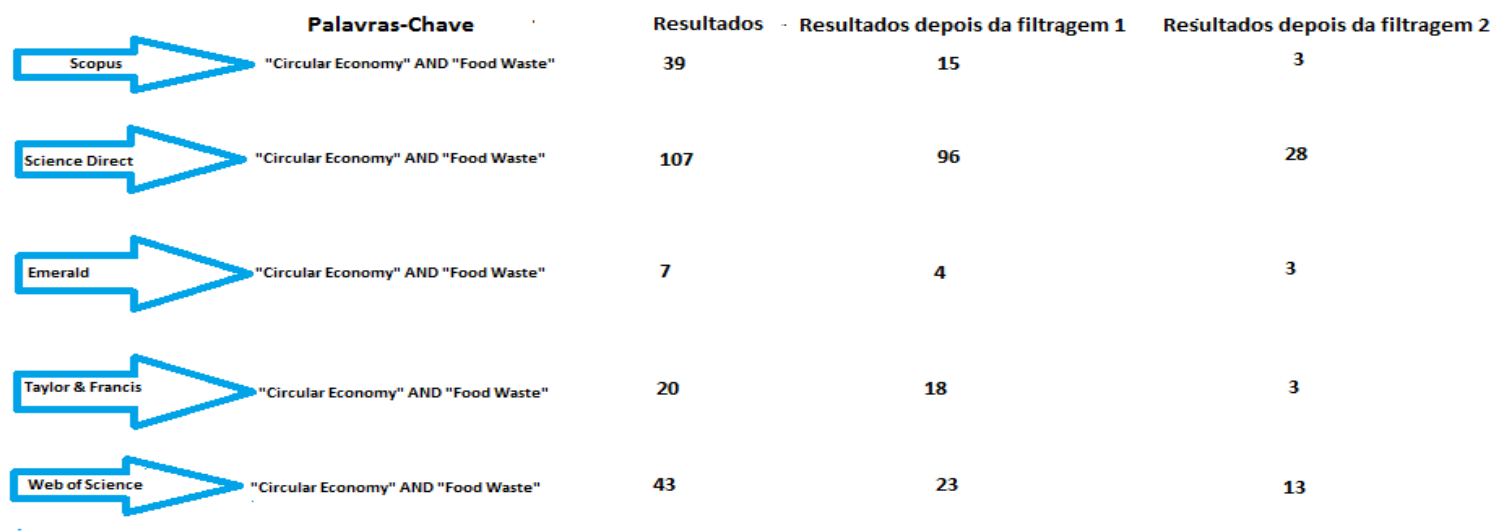

Fonte: Autores.

Em seguida, foi utilizada a técnica de análise de conteúdo de Bardin (1977) para analisar e interpretar os artigos encontrados, uma vez que podem ser ajustados para verificar temas em comum, de acordo com a inquirição de elementos-chave em cada estudo, transformando essas descobertas individuais em novas interpretações (POLIT \& BECK, 2006).

\section{Resultados e discussões}

\subsection{Revisão da literatura internacional}

Os resultados são apresentados considerando as três dimensões analíticas estabelecidas: (i) demografia das publicações, (ii) autores e instituições, e (iii) métodos e técnicas empregados pelos pesquisadores. 
Figura 2- Quantidade de publicações por ano

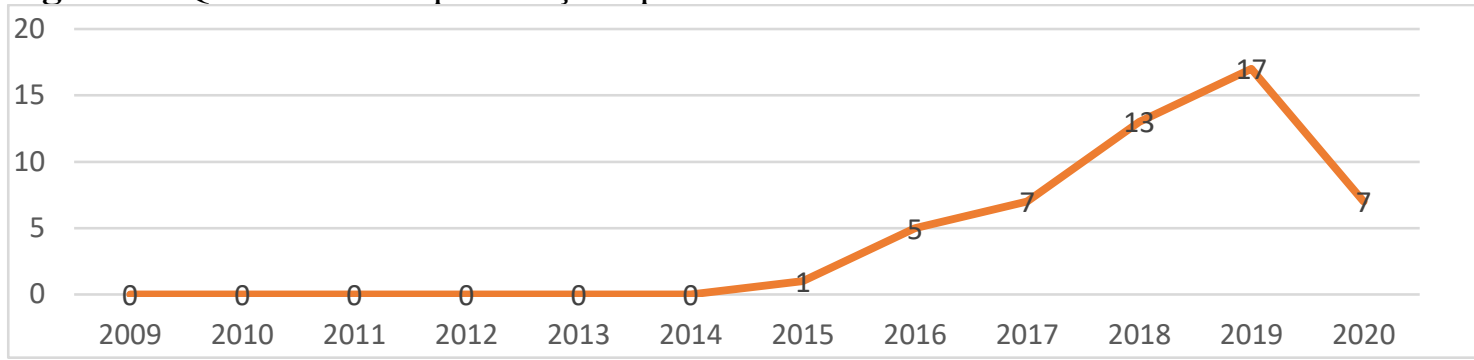

Fonte: Autores.

Para a primeira dimensão (Figura 2), foram considerados os metadados dos artigos científicos disponibilizados nas bases de dados consultadas nesta revisão. Assim, quando se analisa a evolução anual da produção científica sobre $\mathrm{o}$ tópico, constata-se o pico de 17 publicações em 2019 e um aumento das publicações entre 2014 e 2019. Esse período coincide com as discussões sobre a segurança alimentar da zona do Euro, realizadas após a profunda crise alimentar que aconteceu no mundo, particularmente nos países pobres entre 2015 e 2019.

A Figura 2 ilustra que existe um interesse recente e crescente de pesquisadores na condução dos desperdícios alimentares sob a ótica da EC. Constata-se, aparentemente, que no início de 2020, teve uma redução das publicações, isso devido ao recorte temporal considerado até 31 de março de 2020.

Quando se observa os periódicos nos quais os estudos foram publicados, constata-se o caráter interdisciplinar do tema Food waste versus Circular Economy, que são as principais palavraschave deste estudo. Os 50 artigos encontrados foram publicados em um total de 26 periódicos. Apenas 6 deles publicaram mais de um estudo relacionado ao tópico em análise conforme a Tabela 1, sendo 10 artigos no Journal Procedia, 5 no Journal of Cleaner Production, 5 no journal Sustainability 3 no journal Science of the Total Environment, 3 no Journal Ressources Conservation \& Recycling e 4 no journal Waste Management. Esse caráter interdisciplinar fica claro ao analisar a categoria dos periódicos.

Tabela 1- Quantidade de publicações por categoria dos periódicos

\begin{tabular}{|l|c|c|l|}
\hline Qt & CiteScore & Citações em 2018 & Revistas Científicas \\
\hline 10 & - & - & Procedia \\
\hline 5 & 7,32 & 43.324 & Journal of Cleaner Production \\
\hline 5 & 3,01 & 13.880 & Sustainability \\
\hline 4 & 6,15 & 40.039 & Waste Management \\
\hline 3 & 6,82 & 4.096 & Resources, Conservation \& Recycling \\
\hline 3 & 5,92 & 40.039 & Science of the Total Environment \\
\hline
\end{tabular}

Fonte: Autores.

O Journal Procedia mantém a supremacia do jornal que mais divulga sobre o assunto. Esta pesquisa destaca este periódico como o principal veículo para disseminar a pesquisa científica em desperdício alimentar sob a ótica da EC. Outros periódicos também se interessaram pelo tópico conforme se observa na Tabela 1. Vale ressaltar que são periódicos de diferentes partes do 
mundo, principalmente da Europa, e que possuem diferentes fatores de impacto. $\mathrm{O}$ CiteScore (a métrica desenvolvida pela Scopus para medir o impacto dos periódicos científicos) e o número de citações obtidas em 2018 (dados coletados no site da Scopus) foram solicitados nesses principais periódicos.
Os 50 artigos foram escritos por um total de 214 autores, sendo que apenas 2 deles participaram de mais de uma pesquisa sobre o tópico em revisão (Tabela 2). Isso indica que não há uma tradição de pesquisa por uma determinada universidade ou grupo de pesquisa. Sendo os restantes dos autores com apenas 1 artigo publicado.

Tabela 2- Quantidade de autores por universidade.

\begin{tabular}{|l|l|l|l|}
\hline Quantidades & Autores & Países & Universidades \\
\hline 2 & Slorach & Reino Unido & Universidade de Manchester \\
\hline 2 & Corrado & Itália & $\begin{array}{l}\text { Universidade Católica Del } \\
\text { Sacro Cuore }\end{array}$ \\
\hline
\end{tabular}

Fonte: Autores.

Já a Tabela 3 mostra os principais países com maiores quantidades de publicação. Constata-se a predominância dos países europeus, como a Itália, com 15 publicações, e o Reino Unido com 11 publicações.

Tabela 3- Quantidade de publicação por país

\begin{tabular}{|c|c|}
\hline Países & Quantidades de publicação \\
\hline Itália & 15 \\
\hline Reino Unido & 11 \\
\hline Espanha & 6 \\
\hline Holanda & 4 \\
\hline Suécia & 4 \\
\hline Nova Zelândia & 4 \\
\hline EUA & 3 \\
\hline China & 2 \\
\hline Finlândia & 2 \\
\hline Cingapura & 1 \\
\hline Alemanha & 1 \\
\hline Taiwan & 1 \\
\hline Irlanda & 1 \\
\hline Finlândia & 2 \\
\hline Nova Zelândia & 4 \\
\hline Canadá & 1 \\
\hline Dinamarca & 1 \\
\hline Romênia & 1 \\
\hline Croácia & 1 \\
\hline Portugal & 1 \\
\hline Áustria & 1 \\
\hline Letónia & 1 \\
\hline Rússia & 1 \\
\hline Arábia Saudita & 1 \\
\hline
\end{tabular}


Fonte: Autores.

Observa-se que a Itália e o Reino Unido se interessam mais pelo assunto do que quaisquer outros países europeus e há pouca publicação norte-americana, perfazendo um total de 4 . Também não consta nenhuma publicação sobre o tema no continente africano, onde existem mais problemas de insegurança alimentar, segundo a FAO (2018), e na América Latina, onde existe muito desperdício e perda de alimentos (FAO et al., 2019).

Além desses países listados, outros 22 também foram representados nos estudos, sendo a Espanha, com 6 publicações, a Holanda, a Suécia e a
Nova Zelândia com 4 publicações cada um e 2 publicações na China e na Finlândia. Dentre eles, não consta nenhum artigo brasileiro escrito, o que aponta uma escassez de pesquisa sobre o tema em continentes que vivenciam muito o problema do desperdício, como demostraram os dados coletados.

A segunda dimensão analítica desta revisão teve como propósito caracterizar as palavras-chave abordadas. Para identificação dos temas, as palavras-chave dos estudos foram analisadas no wordart.net/create conforme a Figura 3.

Figura 3- Nuvem de palavras-chave dos artigos da revisão sistemática

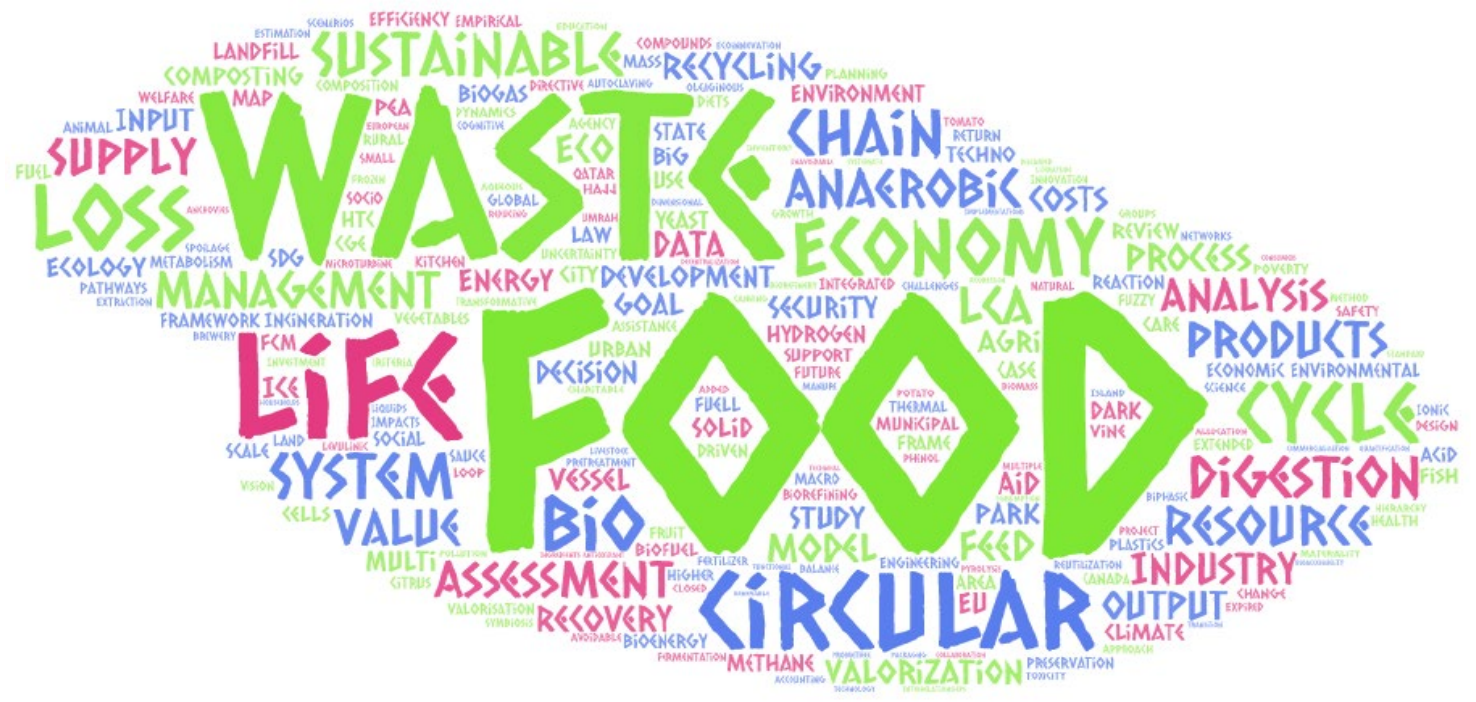

Fonte: Autores.

Esta nuvem de palavras ilustra com que frequência os termos são repetidos como palavras-chave e deve-se lembrar que, no conceito de nuvem de palavras, quanto mais vezes o termo se repete, maior é a representação da palavra. Destarte, a análise das palavraschave escolhidas pelos autores é útil para identificar os sujeitos da pesquisa. A palavra-chave "Food" é a que mais se repete nos artigos, aparecendo em 63 oportunidades. Em seguida, "Waste" com 58, "Circular" e "Economy" aparecem repetidamente 20 vezes.
Os termos "Food", "Waste", "Circular" e "Economy" não são de surpreender entre os mais citados, pois foram as palavras inseridas nos mecanismos de pesquisa. No entanto, as palavras "Digestion" "Anaerobic", "Life" "Cycle", que aparecem respectivamente 9 vezes são os principais meios de valorização dos resíduos alimentares sugeridos pelos pesquisadores, pois vão além de uma mera reciclagem dos resíduos alimentares. 
Acerca dos trabalhos que compuseram a RSL, (18\%) são puramente qualitativos, (46\%) utilizaram a abordagem quantitativa e (36\%) restantes utilizaram a abordagem mista. Destaca-se que há, na abordagem quantitativa, o uso de modelos estatísticos inferenciais, enquanto nas pesquisas qualitativas predominaram a revisão de literatura e estudo de caso como procedimentos de pesquisa.

Em relação às técnicas mais utilizadas pelos autores para a coleta de dados (Figura 4), vale ressaltar que quase a metade dos estudos foram baseados na modelagem (52\%). Destaca-se, portanto, a preocupação dos autores em demonstrar a viabilidade prática dos modelos circulares no resgate dos alimentos desperdiçados. $\mathrm{O}$ grande número de revisões de literatura, estudos de caso e experimentos demonstra que os pesquisadores buscam encontrar semelhanças, diferenças conceituais, conhecimentos teóricos bem como modelos que viabilizem a replicabilidade dos achados.

Figura 4- Caracterização das técnicas de pesquisa

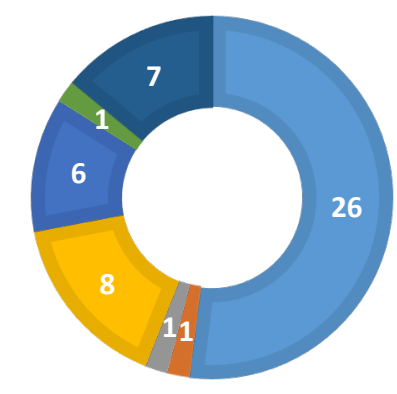

\section{Modelo \\ Revisão de Literatura \\ Estudo de Caso}

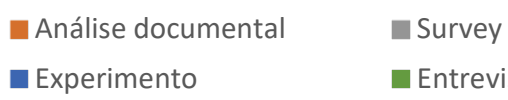

Análise documental

- Survey

Experimento

Fonte: Autores.

Quanto ao enquadramento dos estudos, observou-se que a maioria são de natureza teórico-empírica (90\%) e (10 $\%$ ) de estudos teóricos. O grande número de estudos teórico-empíricos decorre principalmente do fato de os artigos serem baseados em projetos financiados pelos órgãos governamentais $\mathrm{e}$ instituições internacionais da União Europeia. Nesse contexto, esses artigos científicos servem de base no desempenho da implementação dos modelos circulares no âmbito das organizações para a prevenção e valorização dos resíduos alimentares ao longo da cadeia de suprimentos alimentar. São projetos que têm como objetivo desenvolver soluções integradas para gerenciar com eficiência a recuperação dos resíduos alimentares. Os estudos classificados como teóricos se referem, principalmente, ao desenvolvimento de modelos teóricos, em especial, na área da química.

$\mathrm{Na}$ terceira dimensão, as análises que seguem contemplam os 50 estudos identificados, conforme já exposto na seção que apresentou o método utilizado neste trabalho. Na sequência, o Quadro 2 apresenta os objetivos dos artigos categorizados, conforme maior ocorrência de determinado tema ou palavra-chave. 
Quadro 2- Organização dos artigos de acordo com o objetivo categorizado

\begin{tabular}{|c|c|}
\hline Categorias: palavras-chave dos objetivos & Autores \\
\hline $\begin{array}{l}\text { Plataforma de colaboração; simbiose } \\
\text { industrial. }\end{array}$ & $\begin{array}{l}\text { Lowa et al. (2018); Albino et al. (2015); Bas-Bellver et al. } \\
\text { (2020). }\end{array}$ \\
\hline $\begin{array}{l}\text { Estratégia de bioeconomia; estrutura de } \\
\text { monitoramento e avaliação; apoio à } \\
\text { decisão. }\end{array}$ & $\begin{array}{l}\text { Sheppard et al. (2020); Pérez-Camacho et al. (2018); Velenturf } \\
\text { \& Jopson (2019); Erceg \& Margeta (2019). }\end{array}$ \\
\hline Método de autoclave. & Chang et al. (2018). \\
\hline $\begin{array}{l}\text { Gerenciamento dos resíduos de alimentos; } \\
\text { sustentabilidade; avaliação do ciclo de vida } \\
\text { (AVC); prevenção do desperdício de } \\
\text { alimentos. }\end{array}$ & $\begin{array}{l}\text { Slorach et al. (2020); Sala et al. (2017); Li et al. (2016); Van } \\
\text { Bemmel \& Parizeau (2020); Perez-Camacho et al. (2018); } \\
\text { Corrado \& Sala (2018); Garcia-Garcia et al. (2019); Martindale } \\
\text { \& Schiebel (2017); Notarnicola et al. (2017); Kubule et al. } \\
\text { (2019); Bas-Bellver et al. (2020); Laso et al. (2016). }\end{array}$ \\
\hline $\begin{array}{l}\text { Políticas de redução do desperdício de } \\
\text { alimentos. }\end{array}$ & $\begin{array}{l}\text { Read et al. (2020); Irani et al. (2018); Liberti et al. (2018). } \\
\text { Jurgilevich et al. (2016); Bas-Bellver et al. (2020); Philippidis et } \\
\text { al. (2019). }\end{array}$ \\
\hline $\begin{array}{l}\text { Biorrefinaria de resíduos de alimentos; } \\
\text { digestão anaeróbica (DA); biocombustível; } \\
\text { produção de energia. }\end{array}$ & $\begin{array}{l}\text { Karthikeyan et al. (2017); Sadhukhan \& Martinez-Hernandez } \\
\text { (2017); Pecorini et al. (2018); Rehan et al. (2017); Pérez- } \\
\text { Camacho et al. (2018); Rada et al. (2019). }\end{array}$ \\
\hline Iniciativas de assistência alimentar. & $\begin{array}{l}\text { Hebinck et al. (2018); Tikka (2019); Liberti et al. (2018); Kubule } \\
\text { et al. (2019); Jurgilevich et al. (2016) }\end{array}$ \\
\hline $\begin{array}{l}\text { Tratamento de resíduos; tratamento } \\
\text { químico; valorização. }\end{array}$ & $\begin{array}{l}\text { Li et al. (2016); Sadhukhan \& Martinez-Hernandez (2017); } \\
\text { Neves et al. (2019); Castrica et al. (2019); Jurgilevich et al. } \\
\text { (2016); Laso et al. (2019); }\end{array}$ \\
\hline $\begin{array}{l}\text { Estudos comparativos entre digestão } \\
\text { anaeróbica } \quad \text { (DA), } \\
\text { compostagem, aterro sanitário. }\end{array}$ & Slorach et al. (2018). \\
\hline Hierarquia de resíduos. & Hoehn et al. (2019). \\
\hline Segurança alimentar e regulamentações. & $\begin{array}{l}\text { Lucifero (2016); Velenturf \&Jopson (2019); Mihai \& Grozavu } \\
\text { (2019); Erceg \& Margeta (2019); Jurgilevich et al. (2016); } \\
\text { Philippidis et al. (2019). }\end{array}$ \\
\hline $\begin{array}{l}\text { Sustentabilidade da cadeia alimentar de } \\
\text { suprimentos. }\end{array}$ & $\begin{array}{l}\text { Xu \&Wang (2016); Sala et al. (2018); Martindale \& Schiebel } \\
\text { (2017); Jurgilevich et al. (2016); Bas-Bellver et al. (2020); Laso } \\
\text { et al. (2016). }\end{array}$ \\
\hline Quantificação de resíduos de alimentos. & $\begin{array}{l}\text { Corrado \& Sala (2018); Mason-D’Croz et al. (2019); Garcia- } \\
\text { Garcia et al. (2019); Caldeira et al. (2019); Powell \& Chertow } \\
\text { (2018); Secondi et al. (2019); Kubule et al. (2019); Cobo et al. } \\
\text { (2018); Jurgilevich et al. (2016). }\end{array}$ \\
\hline Otimização econômica e ambiental. & $\begin{array}{l}\text { Sala et al. (2018); Rivera et al. (2018); Corrado et al. (2017); } \\
\text { Udugama et al. (2020); Liberti et al. (2018); Mihai \& Grozavu } \\
\text { (2019); Erceg \& Margeta (2019); Cobo et al. (2018); Bas-Bellver } \\
\text { et al. (2020); Laso et al. (2016); Philippidis et al. (2019). }\end{array}$ \\
\hline $\begin{array}{l}\text { Novas embalagens inovadoras } \mathrm{de} \\
\text { alimentos. }\end{array}$ & al. (2018). \\
\hline
\end{tabular}




\begin{tabular}{|l|l|}
\hline $\begin{array}{l}\text { Materialidade de alimentos; } \\
\text { comportamentos dos indivíduos. }\end{array}$ & Van Bemmel \& Parizeau (2020). \\
\hline $\begin{array}{l}\text { Princípios da circularidade no sistema } \\
\text { alimentar. }\end{array}$ & Van Zanten et al. (2019). \\
\hline $\begin{array}{l}\text { Objetivos de desenvolvimento sustentável } \\
\text { das Nações Unidas (ODS); CSAs. }\end{array}$ & Stenton \& Hanmer-Dwight (2019); Philippidis et al. (2019). \\
\hline $\begin{array}{l}\text { Modelos tecnológicos inovadores; } \\
\text { valorização de recursos; modelos de } \\
\text { simulação. }\end{array}$ & $\begin{array}{l}\text { Velenturf \& Jopson (2019); Irani et al. (2018); Corrado et al. } \\
\text { (2017); Garcia-Garcia et al. (2020); Caldeira } \text { et al. (2019); Powell } \\
\text { \& Chertow (2018); Udugama et al. (2020); Secondi et al. (2019); } \\
\text { Liberti et al. (2018); Erceg \& Margeta (2019). Reike et al. } \\
\text { (2018); Philippidis et al. (2019); Rehan et al. (2017); Garre et al. } \\
\text { (2020). }\end{array}$ \\
\hline
\end{tabular}

Fonte: Autores.

Verificou-se que as categorias "Gerenciamento dos resíduos de alimentos; sustentabilidade; avaliação do ciclo de vida (AVC); prevenção do desperdício de alimentos", "Modelos tecnológicos inovadores; valorização de recursos; modelos de simulação", "Quantificação do desperdício de alimentos", "Otimização econômica e ambiental", "Biorrefinaria de resíduos de alimentos; digestão anaeróbica; biocombustível; produção de energia", "Tratamento de resíduos; tratamento químico; valorização", "Políticas de redução do desperdício de alimentos" e "Segurança alimentar e regulamentações" são os temas emergentes com maior incidência nas pesquisas. Portanto, as categorias com menor destaque indicam oportunidades de pesquisa para estudos futuros, bem como temas que obtiveram menor atenção nos últimos anos para a área pesquisada. Até agora, há poucos estudos em que se exploram os princípios da circularidade apontado pela RSL.

\subsection{Agenda de pesquisa}

O Quadro 3 apresenta as proposições de pesquisas futuras levantadas pelos autores dos artigos analisados na RSL, onde há direcionamentos relevantes sugeridos. Elas foram agrupadas em categorias, de maneira a mostrar qual o tipo de tema de sugestão de estudo futuro mais relevante.

Quadro 3- Organização dos artigos de acordo com as sugestões para trabalhos futuros

\begin{tabular}{|c|c|}
\hline $\begin{array}{l}\text { Categorias de temas propostos para trabalhos } \\
\text { futuros }\end{array}$ & Autores \\
\hline $\begin{array}{l}\text { Existem barreiras não técnicas a serem superadas; } \\
\text { barreiras financeiras. }\end{array}$ & $\begin{array}{l}\text { Lowa et al. (2018); Sheppard et al. (2020); Velenturf \& } \\
\text { Jopson (2019); Philippidis et al. (2019). }\end{array}$ \\
\hline $\begin{array}{l}\text { Fertilizantes; biogás; refinaria integrada; geração } \\
\text { de energia; rede nacional; autoconsumo. }\end{array}$ & $\begin{array}{l}\text { Chang et al. (2018); Karthikeyan et al. (2017); Hoehn et } \\
\text { al. (2019); Pecorini et al. (2018); Philippidis et al. (2019). }\end{array}$ \\
\hline $\begin{array}{l}\text { Otimização econômica e ambiental; modelagem } \\
\text { matemática; rastreamento; quantificação; } \\
\text { mapeamento; projeção de modelos preditivos; } \\
\text { seleção de tecnologias para a CSA; inovação; } \\
\text { avaliação de ciclo de vida (ACV). }\end{array}$ & $\begin{array}{l}\text { Garre et al. (2020); Karthikeyan et al. (2017); Hoehn et } \\
\text { al. (2019); Xu \& Wang (2016); Corrado \& Sala (2018); } \\
\text { Mason-D'Croz et al (2019); Sala et al. (2017); Rivera et } \\
\text { al. (2019); Van Bemmel \& Parizeau (2020); Corrado et al. } \\
\text { (2017); Caldeira et al. (2019); De Laurentiis et al. (2018); } \\
\text { Powell \& Chertow (2018); Kubule et al. (2019); Maso et } \\
\text { al. (2016); Rehan et al. (2017). }\end{array}$ \\
\hline
\end{tabular}




\begin{tabular}{|c|c|}
\hline $\begin{array}{l}\text { A coleta separada do resíduo de alimentos para } \\
\text { tratamento via digestão anaeróbica (DA) deve ser } \\
\text { incentivada. }\end{array}$ & $\begin{array}{l}\text { Slorach et al. (2020); Slorach et al. (2018); Pecorini et al. } \\
\text { (2018); Pérez-Camacho et al. (2018); Philippidis et al. } \\
\text { (2019). }\end{array}$ \\
\hline $\begin{array}{l}\text { A prevenção ainda é o melhor caminho para obter } \\
\text { benefícios ambientais e econômicas significativas; } \\
\text { tomada de decisão. }\end{array}$ & $\begin{array}{l}\text { Slorach et al. (2020); Liberti et al. (2018); Martindale \& } \\
\text { Schiebel (2017); Rehan et al. (2017). }\end{array}$ \\
\hline $\begin{array}{l}\text { Minimização; impacto ambiental; acesso aos } \\
\text { alimentos; políticas de redução de resíduos na } \\
\text { CSA. }\end{array}$ & $\begin{array}{l}\text { Read et al. (2020); Mason-D’Croz et al. (2019); Mihai } \\
\text { \&Grozavu (2019); Cobo et al. (2019); Jurgilevich et al. } \\
\text { (2016); Bas-Bellver et al. (2020); Li et al. (2016). }\end{array}$ \\
\hline $\begin{array}{l}\text { Legislação ambiental específica; metas; } \\
\text { valorização dos resíduos; políticas públicas para } \\
\text { EC. }\end{array}$ & $\begin{array}{l}\text { Karthikeyan et al. (2017); Mason-D’Croz et al. (2019); } \\
\text { Pérez-Camacho et al. (2018); Jurgilevich et al. (2016); } \\
\text { Rehan et al. (2017). Li et al. (2016). }\end{array}$ \\
\hline $\begin{array}{l}\text { Possíveis vias de investigação seriam o papel de } \\
\text { narrativas como "o direito à alimentação" de } \\
\text { "dentro" do banco de alimentos e as novas relações } \\
\text { dos movimentos sociais com formas de práticas de } \\
\text { assistência alimentar. }\end{array}$ & Hebinck et al. (2018). \\
\hline A mudança de responsabilidade social do Estado. & Tikka (2019); Mason-D’Croz et al. (2019). \\
\hline $\begin{array}{l}\text { Aplicação do simbiose industrial (SI) em práticas } \\
\text { conforme as realidades de cada cidade/região. }\end{array}$ & Albino et al. (2015); Jurgilevich et al. (2016). \\
\hline $\begin{array}{l}\text { Necessidade de parcerias transformadoras } \\
\text { alinhadas aos objetivos de desenvolvimento } \\
\text { sustentável das Nações Unidas (ODS). }\end{array}$ & Stenton \& Hanmer-Dwight (2019). \\
\hline Compostagem & Erceg \& Margeta (2019); Philippidis et al. (2019). \\
\hline Valorização do resíduo de alimentos/orgânicos. & $\begin{array}{l}\text { Irani et al. (2018); Sadhukhan \& Martinez-Hernandez } \\
\text { (2017); Garcia-Garcia et al. (2019); Bas-Bellver et al. } \\
\text { (2020); Philippidis et al. (2019). }\end{array}$ \\
\hline $\begin{array}{l}\text { Comercialização das tecnologias de produção de } \\
\text { energias renováveis. }\end{array}$ & Udugama et al. (2020). \\
\hline $\begin{array}{l}\text { Pesquisas referentes ao desperdício no âmbito dos } \\
\text { consumidores; dados únicos; produtos específicos; } \\
\text { necessidade de conhecimentos sobre outras } \\
\text { cadeias de suprimentos. }\end{array}$ & Secondi et al. (2019). \\
\hline Operação em sinergia. & Liberti et al. (2018); Jurgilevich et al. (2016). \\
\hline $\begin{array}{l}\text { As rotas tradicionais (compostagem doméstica, } \\
\text { alimentação animal, recuperação de resíduos } \\
\text { domésticos) devem ser melhoradas e apoiadas pela } \\
\text { comunidade rural. }\end{array}$ & Mihai \&Grozavu (2019). \\
\hline $\begin{array}{l}\text { Medidas socioeconômicas e } \text { institucionais; } \\
\text { redefinição de qualidade de vida. }\end{array}$ & Van Zanten et al. (2019). \\
\hline $\begin{array}{l}\text { Os sistemas bifásicos aquosos, compostos por } \\
\text { líquidos iônicos bistriflimida e carboidratos são } \\
\text { uma plataforma promissora para separar } \\
\text { simultaneamente os carboidratos e antioxidantes } \\
\text { do resíduo de alimentos. }\end{array}$ & Neves et al. (2020). \\
\hline
\end{tabular}




\begin{tabular}{|l|l|}
\hline $\begin{array}{l}\text { Conceptualização dos modelos circulares através } \\
\text { do enfoque nas opçães de retenção de histórico e } \\
\text { valor de recursos. }\end{array}$ & Reike et al. (2018). \\
\hline $\begin{array}{l}\text { Encontrar um equilíbrio entre quantidades e } \\
\text { qualidades, além de explorar as possibilidades de } \\
\text { implementação na ACV. }\end{array}$ & Notarnicola et al. (2017). \\
\hline Armazenamento e processamento. & Castrica et al. (2019); Bas-Bellver et al. (2020) \\
\hline $\begin{array}{l}\text { Métodos de digestão anaeróbica (DA) e reator de } \\
\text { carbonização hidrotérmica (HTC) em países de } \\
\text { renda média. }\end{array}$ & Rada et al. (2019). \\
\hline
\end{tabular}

Fonte: Autores.

No total, houve 23 categorias de trabalhos que foram os temas sugeridos por autores para pesquisas futuras. Notase que as categorias dos trabalhos relevantes com maior destaque foram "Otimização econômica e ambiental; modelagem matemática; rastreamento; quantificação; mapeamento; projeção de modelos preditivos; seleção de tecnologias para a CSA; inovação; avaliação de ciclo de vida (ACV)", "A coleta separada do resíduo de alimentos para tratamento via digestão anaeróbica (DA) deve ser incentivada", "A prevenção; tomada de decisão", "Minimização do impacto ambiental e a melhoria do acesso aos alimentos; políticas de redução; CSA", "Legislação específica; metas; resíduos; políticas públicas" e "Valorização do resíduo de alimentos".

Pode-se inferir que tais categorias que apresentaram maior destaque devem ser levadas em consideração nos trabalhos futuros para o gerenciamento eficaz do resíduo de alimentos sob a ótica da EC. Adicionalmente, as categorias constantes do Quadro 3 mostram a relevância de temas sobre o desperdício de alimentos no quadro da EC apresentados por autores da área para elaboração de trabalhos futuros. Diante da descrição e discussão realizadas até este ponto, nota-se a grande diversidade de trabalhos apresentados nos diferentes periódicos internacionais, bem como a importância que tal tema representa para o cenário de segurança alimentar no mundo, particularmente nos países pobres.

Este estudo investigou a situação atual de pesquisas relativas ao gerenciamento de resíduos alimentares utilizando diferentes modelos de EC para mitigar o avanço destes últimos na nossa sociedade. Os métodos circulares apontados pelos diferentes pesquisadores são eficientes, mas custosos. Nesse sentido, os pesquisadores sugerem para pesquisa futura uma sinergia entre os atores da CSA e atores dos países desenvolvidos e em desenvolvimento, uma conceitualização dos modelos circulares, utilizando o enfoque nas opções de retenção de histórico e valor de recursos, um equilíbrio entre quantidades $\mathrm{e}$ qualidades, além de explorar as possibilidades de implementação da ACV e políticas de compartilhamento de excedentes de alimentos. Enquanto isso, outros pesquisadores sugerem a implementação dos instrumentos de recuperação e valorização dos resíduos nos países com baixa renda, onde registram-se os maiores desperdícios evitáveis e inevitáveis (FAO, 2018).

Os estudos mostraram que várias técnicas de valorização foram realizadas em diferentes países desenvolvidos, mas encontram-se ainda em um estado embrionário por causa dos limites financeiros, de uma frágil legislação 
ambiental vigente e da falta de políticas públicas rigorosas dos resíduos. Observa-se que as sugestões dos pesquisadores foram frutíferas para a comunidade acadêmica, pois através dessa RSL percebe-se que faltam ainda estudos em prevenção, recuperação e valorização dos resíduos alimentares nos países em desenvolvimento, particularmente no Brasil no campo da EC. Além disso, constata-se que o gerenciamento dos resíduos alimentares no cenário brasileiro perece estar esquecido e, até o momento, não foi encontrada nenhuma publicação dos pesquisadores brasileiros apontando o reaproveitamento e valorização dos resíduos alimentares nas literaturas internacionais na esfera da EC, considerando os critérios de inclusão e exclusão definidos para essa RSL.

Espera-se que com mais pesquisas acadêmicas, os princípios da circularidade façam parte das prioridades das políticas públicas brasileiras, já que existe há uma década a Política Nacional dos Resíduos Sólidos (PNRS) no Brasil. Destarte, pode assistir-se a uma mitigação dos desperdícios, transformando-os em novas matériasprimas, de modo a minimizar o impacto ambiental e estimular um crescimento da economia mundial, reduzindo a geração de resíduos alimentares e criando novos empregos não apenas nos países desenvolvidos, mas também em países em desenvolvimento.

Dos 50 artigos analisados a partir da RSL, as lacunas de pesquisa identificadas apontam que a maioria dos estudos se concentrou em países desenvolvidos. Também, não foram identificados estudos sobre desperdícios alimentares no âmbito da EC em países africanos que são os mais vulneráveis em situação de insegurança alimentar (FAO, 2018). Além disso, observa-se que a maioria dos pesquisadores se preocupa mais com a resolução rápida das questões de desperdício de alimentos em países desenvolvidos e não em países em desenvolvimento que sofrem mais de desperdício de alimentos no início da produção (processamento, distribuição e consumo) (GUSTAVSSON et al., 2011). Também é notória a existência de estudos que relatam casos, principalmente de países desenvolvidos.

Li et al. (2016) ressaltam que a maioria dos países em desenvolvimento não prática ainda de forma completa a reciclagem de resíduos de alimentos. Como resultado, a maioria dos resíduos alimentares se mistura com resíduos sólidos e, em seguida, é depositada em aterros, contribuindo para o aumento das emissões atmosféricas. Além disso, as legislações ambientais permanecem inaplicáveis e a maior parte dos auxílios para atividades e projetos de reciclagem vem das organizações internacionais, enquanto os países em desenvolvimento estabelecem um orçamento baixo para segregar atividades e instalações de tratamento de resíduos. Sendo assim, os problemas de gerenciamento inadequado de resíduos de alimentos em países em desenvolvimento surgem das medidas administrativas incompatíveis e alocações orçamentárias precárias no aprimoramento das atividades de reciclagem.

Nesse contexto, a gestão de resíduos de alimentos está seriamente ausente nas legislações e regulamentos dos países em desenvolvimento, onde faltam políticas, regulamentos e planos oficiais de EC para os resíduos de alimentos (KINOBE et al., 2015).

Constata-se que ainda há um longo caminho a percorrer no contexto de redução do desperdício de alimentos, devido à produção constante das grandes indústrias agroalimentares e aos efeitos de marketing que incentivam frequentemente o consumo de novos produtos no mercado. Por outro lado, assiste-se a uma rápida diminuição dos recursos naturais do planeta e o aumento da insegurança alimentar, 
particularmente nos países em desenvolvimento.

Os pesquisadores devem pensar em realizar levantamentos de campo integrando todos os atores da cadeia de suprimentos, por meio de entrevistas, workshops, surveys, grupo focais $\mathrm{e}$ estudos de caso, etnográficos e fenomenológicos, a fim de entender melhor as principais causas do desperdício de alimentos nas cadeias de valor e de produção e solucioná-las em vez de focar apenas em modelos positivistas, conforme observado na RSL.

\section{Considerações finais}

A EC é uma das principais diretrizes para os países, cidades e empresas avançarem para o desenvolvimento sustentável nos próximos anos (GRAVAGNUOLO et al., 2019). Nesse contexto, é necessária a busca pela legitimidade, respeitando as regras e regulamentações ambientais vigentes em cada país, a fim de mitigar os problemas ligados aos desperdícios alimentares, transformando-os em insumos, matérias-primas e energia ao longo das cadeias de suprimentos alimentares.

Este trabalho analisou o estado da arte da EC no desperdício de alimentos na literatura internacional. Nesse sentido, foram pesquisados artigos científicos publicados em inglês em cinco bases: Science Direct, Scopus, Web of Science, Scopus, Taylor \& Francis e Emerald. As etapas foram descritas, os filtros e os critérios de inclusão e exclusão foram detalhados e, ao final da pesquisa, foram analisados 50 artigos sobre o assunto (Quadro1).

Existe um interesse crescente entre os acadêmicos e profissionais da área e constata-se que os autores/instituições mais produtivas se concentram na Europa (Tabela 3), possivelmente porque nesses países existem diretrizes para a comunidade europeia e legislações tratando de economia circular e food waste. A maioria dos estudos concentrou-se nas modelagens matemáticas que são as mais promissoras na redução de resíduos de alimentos segundo os autores. Também, outros autores focalizaram-se nas tecnologias inovadoras, como a utilização da Internet das coisas na prevenção dos desperdícios.

Os autores abordaram as técnicas de reaproveitamento dos resíduos alimentares como reciclagem, quantificação, digestão anaeróbica, avaliação de ciclo de vida, compostagem, simbiose industrial (Figura 3). Além disso, destaca-se que os métodos mais usados pelos pesquisadores foram a abordagem quantitativa $(46 \%)$, enquanto poucos autores utilizaram a abordagem qualitativa $(18 \%)$ e os demais, a abordagem mista (36\%).

Adicionalmente, foi apresentada uma agenda de pesquisa fornece a orientação para novos estudos que podem ser voltados para as mudanças de paradigma, de envolvimento dos stakeholders, dos atores das CSAs, dos políticos, dos formuladores de decisão, dos consumidores e da sociedade em geral para promover a circularidade por meio da legislação e regulamentos; para o monitoramento completo e análise por meio dos indicadores quantitativos de desempenho ambiental e para a aplicabilidade dos modelos conceituais e projetos (Quadro 3).

A partir desta revisão de literatura, percebe-se que há ainda poucos estudos referentes à $\mathrm{EC}$ do desperdício de alimentos em cadeias de suprimentos, principalmente no que se refere a países em desenvolvimento e com foco em EC, tendo em vista que este é um conceito relativamente recente na literatura, com pouca consolidação teórica. Os resíduos alimentares fazem parte do ciclo biológico da EC e podem 
ser revalorizados e reinseridos na mesma, ou em outras cadeias produtivas a fim de mitigar o problema dos resíduos e aumento de emissões atmosféricas. Demonstrar o estado da arte sobre o tema, bem como lacunas a serem desenvolvidas em estudos futuros podem orientar pesquisadores em relação às temáticas que ainda não estão exploradas no contexto da $\mathrm{EC}$, bem como indicar a gestores possíveis caminhos para a adoção da EC focada em desperdícios alimentares.

Além disso, a recente revisão de literatura desenvolvida por Dora et al. (2021), mostrou que existe poucos estudos em relação à EC do desperdício de alimentos nos países desenvolvidos do que em países subdesenvolvidos. Esses achados corroboram com os resultados encontrados em nossa RSL. Isso deve chamar a atenção dos profissionais da área para ver qual caminho da EC pode corresponder ao contexto dos países em desenvolvimento na prevenção e redução das perdas e desperdícios alimentares.

Enquanto implicações práticas, o presente estudo pode auxiliar, também, os gestores a desenvolverem políticas públicas e diretrizes a respeito de como agregar valor às organizações, nos âmbitos econômico, social e ambiental, a partir da redução do desperdício de alimentos para fins de orientar os atores da cadeia de suprimentos de alimentos a se beneficiarem de um sistema alimentar circular e saudável e regenerativo.

As limitações deste trabalho referem-se principalmente às escolhas feitas em relação ao protocolo de busca escolhido, aos filtros aplicados, ao recorte temporal e às bases científicas selecionadas. Também, o trabalho não esgotou a literatura nacional e internacional (periódicos, bases, anais de eventos, teses, dissertações, livros). Além das agendas de pesquisa já sugeridas, estudos futuros podem escolher outras bases e protocolos para comparar resultados. Acredita-se que a EC merece ganhar a robustez imprescindível para continuar crescendo, não apenas na academia, mas também em organizações públicas e privadas. Estudos futuros podem utilizar outros protocolos como o Methodi Ordinatio, Procknow C, Metanálise entre outros, a fim de selecionar e filtrar as fontes de dados. Também podem definir critérios de inclusão e exclusão diferentes, que complementem o período de publicação, e abranjam outros materiais não considerados nessa RSL. Ademais estudos que proponham métodos quantitativos padronizados para a quantificação de desperdícios e que estudem os desperdícios em vários atores da cadeia de suprimentos como: varejistas, atacadistas, restaurantes, cadeias curtas como feiras e o consumidor podem trazer luz às lacunas apresentadas nessa pesquisa.

Por fim, este estudo contribuiu para uma visão teórica geral da evolução das publicações internacionais sobre o food waste, apontando diferentes métodos usados pelos pesquisadores e diferentes modelos circulares desenvolvidos nos países desenvolvidos com seus benefícios sociais, econômicos e ambientais para a comunidade acadêmica e a sociedade em geral.

\section{AGRADECIMENTOS}

Para seu apoio:

Conselho Nacional de Desenvolvimento Científico e Tecnológico (CNPq)

Conselho Nacional de Aperfeiçoamento da Educação Superior (CAPES)

\section{REFERÊNCIAS}

ANNOSI, M. C. BRUNETTA, F.; BIMBO, F.; KOSTOULA, M. Digitalization within food supply chains to prevent food waste. Drivers, barriers and collaboration practices. Industrial 
Marketing Management, v. 93, p. 208220, 2021.

BAKKER, C.; HOLLANDER, M. D.; HINTE, E. V. Products that Last 2.0: Product Design for Circular Business Models. BIS Publishers, 2019.

BARDIN, L. Análise de conteúdo. Lisboa: Edições 70. Obra original publicada em 1977.

BENYUS, J. Mother Nature's School of Design. Choices for Sustainable Living, p. 34-8, 2002.

BERETTA, C.; STOESSEL, F.; BAIER, U.; HELLWEG, S. Quantifying food losses and the potential for reduction in Switzerland. Waste management, v. 33, n. 3, p. 764-773, 2013.

BOULDING, K. E. The economics of the coming spaceship earth. New York, 1966.

CALDEIRA, C.; DE LAURENTIIS, V.; CORRADO, S. Quantification of food waste per product group along the food supply chain in the European Union: a mass flow analysis. Resources, Conservation and Recycling, v. 149, p. 479-488, 2019.

CASTELLANI, V.; SALA, S.; MIRABELLA, N. Beyond the throwaway society: A life cycle-based assessment of the environmental benefit of reuse. Integrated environmental assessment and management, v. 11, n. 3, p. 373-382, 2015.

CREUS, A. C. Prevenção do desperdício alimentar sob a avaliação de ciclo de vida: ferramenta e aplicação em casos práticos. Tese de doutorado. 2018. Disponível em: http://www.producao.ufrj.br/index.php/ en/theses-and-

dissertations/doutorado/2018/678-600/file.. Acesso em 24 fev. 2020.
CRONIN, P.; RYAN, F.; COUGHLAN, $M$. Undertaking a literature review: a step-by-step approach. British journal of nursing, v. 17, n. 1, p. 38-43, 2008.

DELIBERADOR, L. R. Desperdício de alimentos em restaurantes: uma análise em uma instituição universitária. 177 f. Dissertação (Mestrado em Engenharia de Produção) - Universidade Federal de São Carlos, São Carlos, 2019.

DELORENZO, A.; PARIZEAU, K.; VON MASSOW, M. Regulating Ontario's circular economy through food waste legislation. Society and Business Review, 2019.

DE MORAES, C. C.; DE OLIVEIRA COSTA, F. H.; PEREIRA, C. R.; DA SILVA, A. L.; DELAI, I. Retail food waste: Mapping causes and reduction practices. Journal of Cleaner Production, 256, p.120124, 2020.

DE SOUSA JABBOUR, A. B. L.; LUIZ, J. V. R.; LUIZ, O. R.; JABBOUR, C. J. C.; NDUBISI, N. O.; DE OLIVEIRA, J. H. C.; JUNIOR, F. H. Circular economy business models and operations management. Journal of cleaner production, v. 235, p. 1525-1539, 2019.

DHIR, A.; TALWAR, S.; KAUR, P.; MALIBARI, A. Food waste in hospitality and food services: A systematic literature review and framework development approach. Journal of Cleaner Production, v. 270, p. 122861, 2020.

DIAZ-RUIZ, R.; COSTA-FONT, M.; LÓPEZ-I-GELATS, F. Food waste prevention along the food supply chain: A multi-actor approach to identify effective solutions. Resources, Conservation and Recycling, v. 149, p. 249-260, 2019. 
DORA, M.; BISWAS, S.; CHOUDHARY, S.; NAYAK, R.; IRANI, Z. A system-wide interdisciplinary conceptual framework for food loss and waste mitigation strategies in the supply chain. Industrial Marketing Management, v. 93, p. 492508, 2021.

EMF. Towards the Circular Economy: Accelerating the scale-up across global supply chains. World Economic Forum Reports, (January), 64. 2014.

EMF. Growth within: a Circular Economy Vision for a Competitive. Europe, London. 2015.

FANCELLO, G.; MOLA, F.; FRIGAU, L.; SERRA, P.; MANCINI, S.; FADDA, P. A new management scheme to support reverse logistics processes in the agrifood distribution sector. Transportation Research Procedia, 25, 695-715, 2017.

FOOD AND AGRICULTURE ORGANIZATION. The State of Food Insecurity in the World. Rome: FAO. 2018.

FOOD AND AGRICULTURE ORGANIZATION, INTERNATIONAL FUND FOR AGRICULTURAL DEVELOPMENT, UNICEF, WORLD FOOD PROGRAMME, \& WORLD HEALTH ORGANIZATION. The state of food security and nutrition in the World: Safeguarding against economic slowdowns and downturns. FAO. 2019.

FROSCH, R. A.; GALLOPOULOS, N. E. Strategies for manufacturing. Scientific

American, 261(3), 144-153. 1989.

GEISSDOERFER, M.; SAVAGET, P.; BOCKEN, N. M.; HULTINK, E. J. The Circular Economy-A new sustainability paradigm? Journal of cleaner production, 143, 757-768. 2017.

GHISELLINI， P.; CIALANI， C.; ULGIATI, S. A review on circular economy: The expected transition to a balanced interplay of environmental and economic systems. JCP, 114(May 2017), 11-32. Access in: https://doi.org/10.1016/j.jclepro.2015.0 9.007. 2016.

GRAVAGNUOLO, A.; ANGRISANO, M.; FUSCO, G. L. Circular economy strategies in eight historic port cities: Criteria and indicators towards a circular city assessment framework. Sustainability, 11(13), 3512. 2019.

GUARNIERI, P.; CERQUEIRASTREIT, J.; A.; BATISTA, L. C. Reverse logistics and the sectoral agreement of packaging industry in Brazil towards a transition to circular economy. Resources, Conservation and Recycling, v. 153, p. 104541, 2020.

GUIDE JR, V. D. R.; VAN WASSENHOVE, L. N. OR FORUMThe evolution of closed-loop supply chain research. Operations research, v. 57, n. 1, p. 10-18, 2009.

GUSTAVSSON, A.; SVENSSON, M.; JACOBI, F.; ALLGULANDER, C.; ALONSO, J.; BEGHI, E.; GANNON, B. Cost of disorders of the brain in Europe 2010.

European neuropsychopharmacology, 21(10), 718-779. 2011.

KINOBE, J. R.; BOSONA, T.; GEBRESENBET, G.; NIWAGABA, C. B.; \& VINNERÅS, B. Optimization of waste collection and disposal in Kampala city. Habitat International, 49, 126-137. 2015.

KRISTENSEN, H. S.; MOSGAARD, M. A. A review of micro level indicators for a circular economy-moving away 
from the three dimensions of sustainability? Journal of Cleaner Production, v. 243, p. 118531, 2020.

LE BORGNE, G. Sensibilité du consommateur au gaspillage alimentaire: conceptualisation, antécédents, et conséquences (Doctoral dissertation). 2015.

LEMOS, P. Economia Circular como fator de resiliência e competitividade na região de Lisboa e Vale do Tejo. Lisboa, CCDR LVT. 2018.

LEVOSO, A. S.; GASOL, C. M.; MARTÍNEZ-BLANCO, J.; DURANY, X. G.; LEHMANN, M.; GAYA, R. F. Methodological framework for the implementation of circular economy in urban systems. Journal of Cleaner Production, v. 248, p. 119227, 2020.

LI, Y.; JIN, Y., LI, J.; CHEN, Y.; GONG, Y.; LI, Y.; ZHANG, J. Current situation and development of kitchen waste treatment in China. Procedia environmental sciences, 31, 40-49. 2016.

LIEDER, M.; RASHID, A. Towards circular economy implementation: a comprehensive review in context of manufacturing industry. Journal of cleaner production, 115, 36-51. 2016.

LIFSET, R; BOONS, F. Industrial ecology: Business management in a material world. In: The Oxford handbook of business and the natural environment. 2012.

LOVINS, A. B.; LOVINS, L. H; HAWKEN, P. A road map for natural capitalism. Londres. 1999.

LIU, G.; AGOSTINHO, F.; DUAN, H.; SONG, G.; WANG, X.; GIANNETTI, B. F.; LEGA, M. Environmental impacts characterization of packaging waste generated by urban food delivery services. A big-data analysis in Jing-JinJi region (China). Waste Management, v. 117 , p. 157-169, 2020.

LUTTENBERGER, L. R. Waste management challenges in transition to circular economy-case of Croatia. Journal of Cleaner Production, v. 256, p. 120495, 2020.

MCDONOUGH, W.; BRAUNGART, M. Design for the triple top line: new tools for sustainable commerce. Corporate Environmental Strategy, 9(3), 251-258. 2002.

MENA, C.; TERRY, L. A.; WILLIAMS, A.; ELLRAM, L. Causes of waste across multi-tier supply networks: Cases in the UK food sector. International Journal of Production Economics, v. 152, p. 144-158, 2014.

MERLI, R.; PREZIOSI, M.; ACAMPORA, A. How do scholars approach the circular economy? A systematic literature review. Journal of Cleaner Production, v. 178, p. 703-722, 2018.

MOURAD, M. Recycling, recovering and preventing "food waste": Competing solutions for food systems sustainability in the United States and France. Journal of Cleaner Production, v. 126, p. 461477, 2016.

MURRAY, A.; SKENE, K.; HAYNES, $\mathrm{K}$. The Circular Economy: An Interdisciplinary Exploration of the Concept and Application in a Global Context. Journal of Business Ethics, 112. 2015.

ÖSTERGREN, K.; GUSTAVSSON, J.; BOS-BROUWERS, H.; TIMMERMANS, T.; HANSEN, O. J.; MØLLER, H; EASTEAL, S. FUSIONS definitional framework for food waste. Wageningen: FUSIONS

Project. 2014. 
PARFITT, J.; BARTHEL, M.; MACNAUGHTON, S. Food waste within food supply chains: quantification and potential for change to 2050. Philosophical transactions of the royal society B: biological sciences, $v$. 365, n. 1554, p. 3065-3081, 2010.

PAULI, G. A. The blue economy: 10 years, 100 innovations, 100 million jobs. Paradigm publications. 2010.

POLIT, D. F.; BECK, C. T. Essentials of nursing research: Methods, appraisal, and utilization (Vol. 6, No. 8). Lippincott Williams \& Wilkins. 2006.

SANTOS, K. L.; PANIZZONDOS, J.; CENCI, M. M.; GRABOWSKI, G.; JAHNO, V. D. Perdas e desperdícios de alimentos: reflexões sobre $\mathrm{o}$ atual cenário brasileiro. Brazilian Journal of Food Technology, v. 23, 2020.

SAUVÉ, S.; BERNARD, S.; Sloan, P. Environmental sciences, sustainable development and circular economy: Alternative concepts for transdisciplinary research. Environmental Development, 17, 48-56. 2016.

SHEPPARD, P.; GARCIA-GARCIA, G.; STONE, J.; RAHIMIFARD, S. A complete decision-support infrastructure for food waste valorisation. Journal of Cleaner Production, 247, 119608. 2020.

SLORACH, P. C.; JESWANI, H. K.; CUÉLLAR-FRANCA, R.; AZAPAGIC, A. Assessing the economic and environmental sustainability of household food waste management in the UK: Current situation and future scenarios. Science of the Total Environment, 710, 135580. 2020.

SONG, Q.; LI, J.; ZENG, X. Minimizing the increasing solid waste through zero waste strategy. Journal of Cleaner Production, v. 104, p. 199-210, 2015.

STAHEL, W. R. The circular economy. Nature, 531(7595), 435-438. 2016.

SU, B.; GENG, Y.; YU, X. A review of the circular economy in China: moving from rhetoric to implementation. Journal of cleaner production, v. 42, p. 215-227, 2013.

TELLER, C.; HOLWEG, C.; REINER, G.; KOTZAB, H. Retail store operations and food waste. Journal of Cleaner Production, v. 185, p. 981-997, 2018.

TOSTIVINT, C.; DE VERON, S.; JAN, O.; LANCTUIT, H.; HUTTON, Z. V.; LOUBIÈRE, M. Measuring food waste in a dairy supply chain in Pakistan. Journal of Cleaner Production, v. 145, p. 221-231, 2017.

TURNER, R. K.; PEARCE, D. W. The ethical foundations of sustainable economic development. International Institute for Environment and Development. 1990.

UNGER, N.; RAZZA, F. Food waste management (sector) in a circular economy. In Designing Sustainable Technologies, Products and Policies (pp. 127-132). Springer, Cham. 2018.

WESANA, J.; GELLYNCK, X.; DORA, M. K.; PEARCE, D.; DE STEUR, H. Measuring food and nutritional losses through value stream mapping along the dairy value chain in Uganda. Resources, Conservation and Recycling, 150, 104416. 2019.

WILLIAMS, S. C.; GUIMARÃES, C.; ESCRIVÃO JUNIOR, Á. O engajamento para combate ao desperdício de alimentos nos hospitais como estratégia de responsabilidade 
social corporativa. Amazônia, Organizações e Sustentabilidade, v. 8, n. 1, 2019.

WRAP, W. Household food and drink waste in the UK. Report pubished by WRAP. Banbury, UK: WRAP. 2009.
ZHANG, B. Y.; TONG, Y.; SINGH, S., CAI, H.; HUANG, J. Y. Assessment of carbon footprint of nano-packaging considering potential food waste reduction due to shelf life extension. Resources, Conservation and Recycling, 149, 322-331. 2019.

\footnotetext{
${ }^{i}$ Mestre em Gestão Organizacional pela Universidade Federal de Goiás - UFG, Goiás, (Brasil)

ii Doutorado em Engenharia de Produção pela Universidade Federal de Pernambuco - UFPE, Pernambuco, (Brasil). Professora adjunta do curso de Administração da Universidade de Brasília - UnB, Brasília

iii Pós-doutorado em Management \& Organizations (UCLA/USA). Professora em Administração na Universidade de Brasília. Universidade de Brasília - DF.
} 